\section{Before you reach for the bleach...}

\author{
H. Chaudhry, ${ }^{1}$ T. M. Wildan, ${ }^{2}$ S. Popat ${ }_{1}^{3}$ R. Anand ${ }^{4}$ and D. Dhariwal ${ }^{5}$ \\ VERIFIABLE CPD PAPER
}

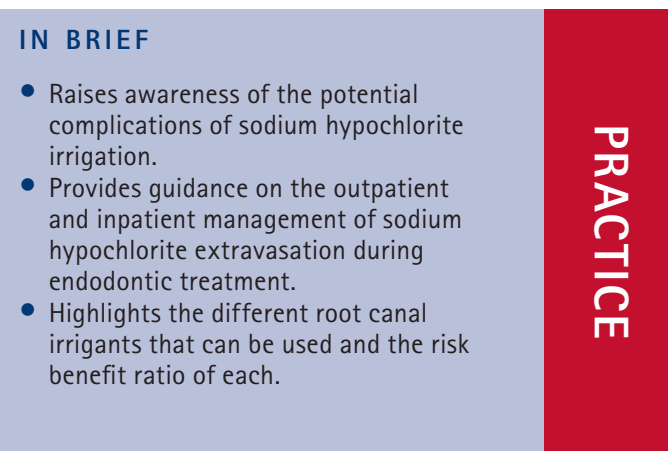

\begin{abstract}
Sodium hypochlorite (bleach) is advocated as an irrigant for use in endodontic therapy for its bacteriocidal and tissue dissolving properties. Extrusion of hypochlorite into the surrounding soft and hard tissues, however, can lead to severe complications, as illustrated in our four case reports. This article considers the risk benefit ratio of the different materials available and advises dental practitioners to ensure patients are aware of the potential risks of the materials used when seeking informed consent. It also aims to provide some guidance on prevention, identification and management of incidents.
\end{abstract}

\section{INTRODUCTION}

Endodontic treatment forms an essential part of routine general dental practice. Sodium hypochlorite is the most commonly used irrigant in endodontics due to its ability to dissolve organic soft tissue in the root canal system and its action as a powerful antimicrobial agent. ${ }^{1}$ However, if the sodium hypochlorite comes into contact with vital tissues it can cause severe inflammation and tissue necrosis. Complications range from minor discomfort to severe tissue necrosis and nerve damage.

We describe our series of four patients who sustained extensive damage following sodium hypochlorite extrusion into the soft tissues during endodontic procedures, seen over a four month period. Three of these patients required hospital admission. This article outlines the clinical cases, discusses the prevention and management of chemical burns relating to hypochlorite irrigation.

\section{CASE REPORT 1}

A 59-year-old woman presented to the Emergency Department following an accidental sodium hypochlorite extrusion

${ }_{1 *-2,5}$ ral and Maxillofacial Surgery; ${ }^{3}$ Consultant in Restorative Dentistry John Radcliffe Hospital, Headington, Oxford, OX3 9DU; ${ }^{4}$ Oral and Maxillofacial Surgery,

Queen Alexandra Hospital, Portsmouth, P06 3LY

*Correspondence to: Dr Heena Chaudhry

Email: heenac_786@hotmail.com

\section{Refereed Paper}

Accepted 30 September 2010

DOI: 10.1038/sj.bdj.2011.90

${ }^{\circledR}$ British Dental Journal 2011; 210: 157-160 during endodontic treatment of the mandibular left first premolar (LL4) by her general dental practitioner (GDP). Root canal therapy was performed in a mesially angulated tooth with access through a porcelain jacket crown. The patient experienced immediate severe pain radiating to the left angle of the mandible during irrigation of the root canal with $1 \mathrm{ml}$ of 5.25\% sodium hypochlorite (neat concentration of household bleach).

The patient presented with a left submandibular swelling and a $1.5 \mathrm{~cm}$ shallow necrotic based ulcer adjacent to the mandibular left canine and premolars (Fig. 1). She also reported numbness in her left lower lip and chin, and also weakness of the left lower lip. A periapical radiograph revealed a perforation of the mesial aspect of the proximal root of the LL4 at the level of the alveolar bone.

On review five days later, the left submandibular swelling had increased to 4 $\mathrm{cm}$ in size with the associated intra-oral ulcer at $3 \mathrm{~cm}$ (Fig. 2). She required hospital admission for intravenous steroids, antibiotics, opioid analgesia and surgical debridement of the necrotic tissue under general anaesthesia. Extensive soft tissue necrosis from the subcutaneous tissue down to the periosteum in the region of the mandibular left incisors to the left second molar region was evident at operation. The mental nerve was oedematous as it exited its foramen with frayed necrotic strands extending to the lower lip (Fig. 3).

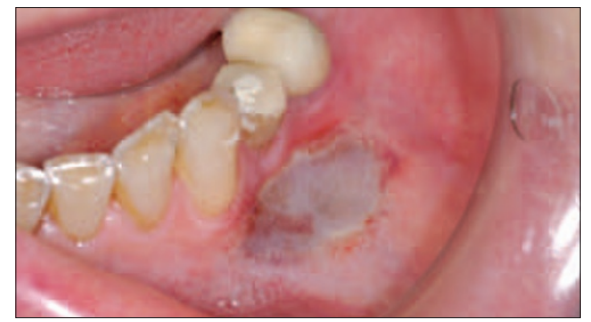

Fig. 1 Necrotic based ulcer adjacent to the mandibular left canine and premolars

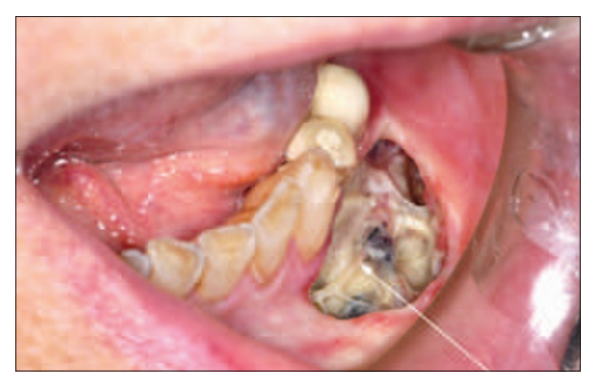

Fig. 2 Further breakdown of necrotic ulcer. Arrow points to exposure of mental nerve

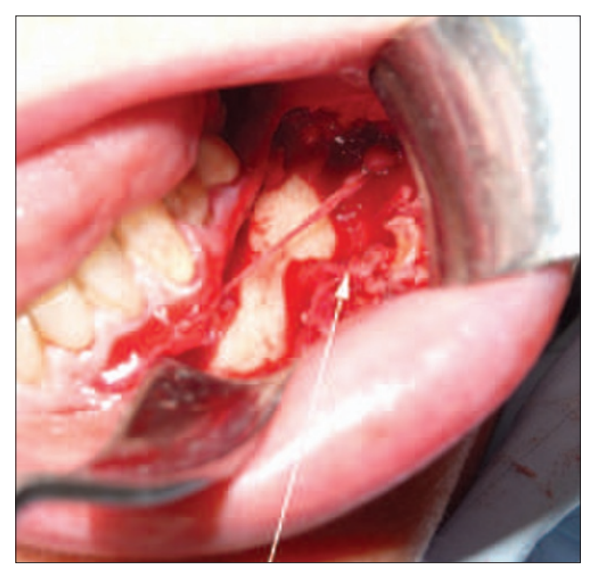

Fig. 3 Oedema of the mental nerve with frayed necrotic strands extending to the lower lip 
The operative findings concurred with the clinical presentation of left marginal mandibular nerve weakness and left mental nerve paraesthesia.

At one month review, she was suffering increasing neuropathic pain in the left cheek and mandible radiating to the left ear and was prescribed nortryptiline. Soft tissue contraction on the left side of her chin was noted following the loss of subcutaneous tissue and fat. Magnetic resonance imaging (MRI) confirmed marrow oedema and reactive hyperplasia of the left mandible secondary to the chemical burn.

At three months, the patient continued to suffer painful dysaesthesia in the region of the left inferior alveolar nerve and had no sensation in the left mental nerve distribution. Weakness of the left marginal mandibular nerve, the motor supply to the lower lip, was noted (Fig. 4). A subcutaneous extra-oral aesthetic defect remained which will require surgical treatment in the future.

\section{CASE REPORT 2}

A 63-year-old woman presented to the Emergency Department with a left facial swelling extending from the lower border of the left mandible up to her left lower eyelid. This was following extrusion of $2 \%$ sodium hypochlorite through the apex of the left maxillary canine (UL3) during endodontic treatment in general dental practice. She also had a loss of sensation in her left cheek in the distribution of the left infra-orbital nerve and weakness of the facial muscles in the region supplied by the buccal branch of the facial nerve. She required hospital admission and treatment with intravenous steroids and antibiotics due to the severity of her facial swelling.

Three months following the sodium hypochlorite accident, the sensation in her left cheek had returned to normal but residual tenderness overlying the apex of the UL3 remained.

\section{CASE REPORT 3}

A 26-year-old woman presented with a chemical burn following sodium hypochlorite (Milton's solution) extrusion through the apex of the maxillary left central incisor (UL1) during root canal treatment. She was initially treated with oral antibiotics by her GDP but presented to the emergency department eight days later with a

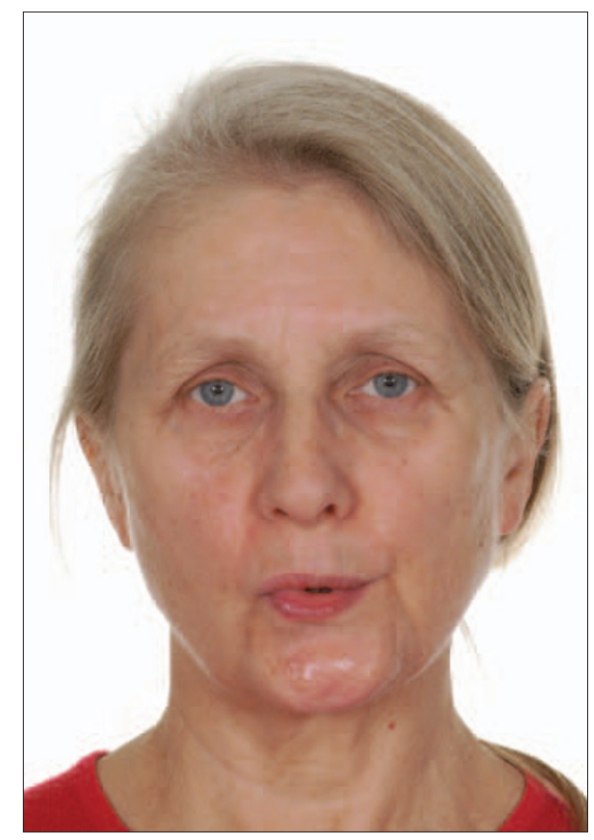

Fig. 4 Weakness of the left lower lip from injury to left marginal mandibular nerve

deep $1.5 \mathrm{~cm}$ diameter necrotic ulcer in the midline of her upper labial sulcus. She also had an area of paraesthesia of the upper lip (Fig. 5).

At three month review, the necrotic ulcer had healed by secondary intention although residual paraesthesia of the upper lip remained.

\section{CASE REPORT 4}

A 38-year-old woman presented to the Emergency Department with pain and a $5 \mathrm{~cm}$ diameter firm left submandibular swelling following sodium hypochlorite irrigation of the mandibular left first premolar (LL4) a few hours earlier (Fig. 6). No rubber dam isolation was used.

On examination, a $1 \mathrm{~cm}$ ulcer in the buccal sulcus adjacent to the LL4 was noted. She complained of altered sensation from the midline of the lower lip and chin to the left angle of the mandible, corresponding to the distribution of the left inferior alveolar nerve. She required hospital admission for two days with intravenous steroids and antibiotics. She also complained of incidental hearing loss from her left ear and of seeing intermittent flashing lights from the left eye although this was unlikely to be attributed to the hypochlorite injury.

At three month review, the swelling had resolved. However, she had developed neuropathic pain and was treated with amitryptiline. The prognosis of the LL4 remained guarded.

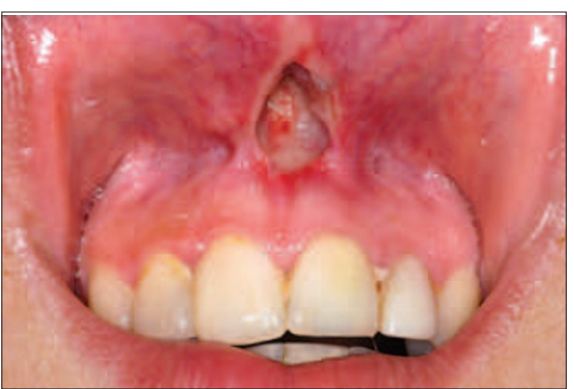

Fig. 5 Necrotic ulcer of the upper labial sulcus

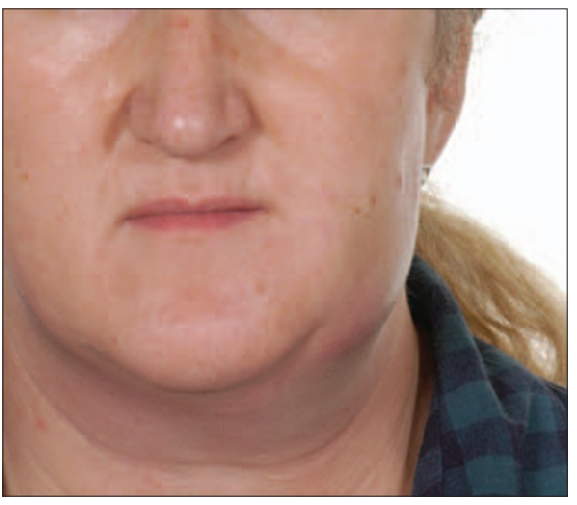

Fig. 6 Left mandibular swelling

Table 1 Sequelae of sodium hypochlorite extrusion beyond the root canal system

\begin{tabular}{|c|c|}
\hline Immediately & Pain $^{3}$ \\
\hline $\begin{array}{l}\text { Few hours } \\
\text { later }\end{array}$ & $\begin{array}{l}\text { - Swelling }{ }^{3} \\
\text { - Ecchymosis } \\
\text { - Bleeding through gingival } \\
\text { margin and tooth }{ }^{4} \\
\text { - Neurological deficit } \\
\text { - } \text { Necrotic ulcer }^{3}\end{array}$ \\
\hline $\begin{array}{l}\text { Few days } \\
\text { later }\end{array}$ & $\begin{array}{l}\text { - Secondary infection }{ }^{3} \\
\text { - Persistent pain } \\
\text { - Persistent neurological deficit }{ }^{5}\end{array}$ \\
\hline
\end{tabular}

\section{DISCUSSION}

Extrusion of sodium hypochlorite beyond the root canal system is not commonly reported but as illustrated in these four cases, it can lead to severe consequences. Damage related to use of sodium hypochlorite can occur in the dental practice in other situations such as accidental spillage leading to damage to clothing, damage to eyes and damage to skin or oral mucosa. ${ }^{2}$

\section{Sequelae of sodium hypochlorite extrusion beyond the root canal system (Table 1)}

All of the four patients in this series complained of immediate pain and three required hospital admission for severe facial swelling after sodium hypochlorite injury. The chemical burn leads to ulceration and tissue necrosis over a period of days due to severe inflammation and 
cellular destruction. ${ }^{4}$ This may require surgical debridement under general anaesthetic as in case 1 .

Sensory neurological deficit may present as anaesthesia, paraesthesia or more disabling dysaesthesia which usually resolves but may take many months. ${ }^{5}$ All our patients developed paraesthesia and two developed persistent neuropathic pain which required tricyclic medication. Chemical damage to motor nerves, principally the facial nerve, ${ }^{6}$ can result in weakness as in case 1 . This may lead to incompetency of the lips and dribbling of fluids and saliva.

Upper airway obstruction due to spillage of hypochlorite during treatment of mandibular molars may lead to life threatening submandibular, submental and sublingual swelling. ${ }^{7,8}$ This would require intubation and surgical decompression. Accidental ingestion of hypochlorite or household bleach can also lead to erythema of the oesophageal mucosa and may progress to perforation of the aerodigestive tract. ${ }^{9,10}$

Anaphylactic reaction to sodium hypochlorite following endodontic treatment requiring intensive care admission had been reported. ${ }^{11}$ This potential allergic reaction should be borne in mind and the dentist should ask about adverse reactions to household bleach products.

\section{Prevention of sodium hypochlorite extrusion}

Points to note to minimise extrusion are:

- Good access cavity design. Ensure adequate coronal preparation

- A pre-operative periapical radiograph to assess angulation of the root canal system

- Remember that a crowned tooth can mask the angulation of the root canal system and incorrect handpiece positioning can lead to root perforation

- Consider access cavity preparation before the placement of rubber dam to avoid poor positioning of the drill

- Use of a side-vent syringe, with a screw-on needle (Luer-Lok ${ }^{\mathrm{TM}}$ ) during irrigation

- Calculate working length accurately and stop if bleeding continues, which might indicate a perforation

- Do not lock the syringe in the canal and keep the end of the syringe well short of the working length
- Use very low digital pressure but not the thumb, to trickle the irrigant into the canal and observe irrigant leaving the canal through the access cavity.

\section{Management of sodium hypochlorite accidents}

The result of accidental sodium hypochlorite spillage or extrusion is unpredictable with no set level in terms of concentration and volume that determine the severity of patient symptoms. Therefore, any incident should be treated with appropriate care and attention (Tables 2 and 3).

There is no published regime for management in hospital. However, steroids are used to dampen the inflammatory response and antibiotics to reduce secondary infection. Wound debridement is required where there is extensive soft tissue necrosis, which if left, would lead to secondary infection. MRI scanning gives further information on bony inflammation, particularly the medullary bone, which may be affected by extrusion of hypochlorite through the apex. There are currently no documented cases of bone loss due to hypochlorite injury.

\section{Root canal irrigants}

The ideal properties of the ideal root canal irrigant are:

- Broad antimicrobial spectrum and high efficacy against aerobic and facultative microorganisms organised in biofilm

- Inactivates endotoxin

- Prevents the formation of smear layer during instrumentation

- Dissolves necrotic pulp tissue and smear layer.

Sodium hypochlorite is the irrigant of choice for many practitioners and endodontists due to its tissue dissolving properties and antimicrobial action from
Table 2 Outpatient management of sodium hypochlorite extravasation

- Stop sodium hypochlorite irrigation

- Irrigate with normal saline or sterile water

- Dress the root canal with non-setting calcium and restore the tooth with reinforced zinc oxide eugeno or glass ionomer to provide a good temporary seal

Outpatient - Long acting local anaesthesia eg bupivacaine

- Analgesia eg Non-steroidal anti inflammatories

- Cold compresses for analgesia

- Hot compresses to improve local circulation ${ }^{3}$

- Antibiotics ${ }^{3}$

- Follow up review

- Referral to oral and maxillofacial surgery unit.

Table 3 Hospital management of sodium hypochlorite extravasation

\begin{tabular}{|c|c|}
\hline $\begin{array}{l}\text { In-patient } \\
\text { management }\end{array}$ & $\begin{array}{l}\text { - Ensure airway patency } \\
\text { - Adequate analgesia eg opi- } \\
\text { oids and anti-inflammatories } \\
\text { - Intravenous steroids up to } \\
48 \text { hours } \\
\text { - Intravenous antibiotics up to } \\
48 \text { hours } \\
\text { - Wound debridement if } \\
\text { required } \\
\text { - Consider MRI. }\end{array}$ \\
\hline
\end{tabular}

the release of chloride ions (Table 4). Concentrations over $0.5 \%$ are cytotoxic. ${ }^{12}$ There is suggestion in the literature that a $1 \%$ solution provides good antimicrobial and tissue dissolving qualities but yet does not have the cytotoxic properties of the 5\% solution. ${ }^{1,13}$ Therefore, dilution of sodium hypochlorite is always recommended. ${ }^{14}$ However, it is relatively ineffective against Enterococcus faecalis, a root canal microorganism. ${ }^{15}$ Sodium hypochlorite also has a high surface tension which prevents deeper penetration of the irrigant into dentinal tubules. ${ }^{16}$ Increasing the temperature of the solution and the time that it is in contact with tissues in the root canal can increase 
its effects as an antibacterial and tissue dissolving agent. ${ }^{1}$

The British Endodontic Society does not recommend one irrigant in particular. ${ }^{19}$ Available irrigants include chlorhexidine, iodine potassium iodide, chelating agents eg EDTA, photo-activated chelating agents eg citric acid, and antibiotic based solutions eg MTAD. 17,18,20-22 Their properties are summarised in Table 4 and 5.

Currently, there are only three cases of adverse drug reaction due to sodium hypochlorite reported to the Medicines and Healthcare products Regulatory Agency (MHRA). ${ }^{23}$ GDPs should be encouraged to report sodium hypochlorite accidents confidentially to the MHRA via their website to help quantify the incidence of this problem.

\section{CONCLUSION}

This paper describes four cases of sodium hypochlorite extrusion and its potential adverse effects. We advocate appropriate informed consent and provide plans for initial outpatient and inpatient management should an extrusion occur.

1. Zehnder M. Root canal irrigants. J Endod 2006 32: 389-398.

2. Spencer H R, Brennan PA, Ike V. Review: the use of sodium hypochlorite - potential complications and their management. Br Dent J 2007; 202: 555-559.

3. Hülsman M, Hahn W. Review: complications during root canal irrigation - literature review and case reports. Int Endod J 2000; 33: 186-193.

4. Mehdipour O, Kleier D J, Averbach R E. Clinical techniques in endodontics: anatomy of sodium hypochlorite accidents. Compend Contin Educ Dent 2007; 28: 544-550.

5. Becking A G. Complications in the use of sodium

Table 5 Properties of other available endodontic irrigants

\begin{tabular}{l|l|l}
\hline Other irrigants & Advantage & Disadvantage \\
\hline $\begin{array}{l}\text { lodide compound } \\
\text { Chelating agent, eg EDTA }\end{array}$ & $\begin{array}{l}\text { Effective at removing dentine } \\
\text { smear layer }\end{array}$ & No antimicrobial activity \\
\hline $\begin{array}{l}\text { Photo-activated chelating agent, } \\
\text { eg citric acid }\end{array}$ & Some antimicrobial activity & \\
\hline $\begin{array}{l}\text { Antibiotic-based, eg MTAD, } \\
\text { Tetraclean }\end{array}$ & $\begin{array}{l}\text { Effective in eliminating } \\
\text { Enterococcus faecalis }\end{array}$ & May develop bacterial resistance \\
\hline
\end{tabular}

hypochlorite during endodontic treatment. Oral Surg Oral Med Oral Pathol 1991; 71: 346-348.

6. Witton R. Neurological complications following extrusion of sodium hypochlorite solution during root canal treatment. Int Endod J 2005; 38: 843-848.

7. Bowden J R, Ethuandan M, Brennan P A. Life threatening airway obstruction secondary to hypochlorite extrusion during root canal treatment Oral Surg Oral Med Oral Pathol Oral Radiol Endod 2006; 101: 402-404.

8. Ziegler D S, Bent G P. Upper airway obstruction induced by a caustic substance found responsive to nebulised adrenaline. J Paediatr Child Health 2001; 37: 524-525.

9. Ross M P, Spiller H A. Fatal ingestion of sodium hypochlorite bleach with associated hypernatraemia and hyperchloraemic metabolic acidosis. Vet Hum Toxicol 1999; 41: 82-86.

10. Arévalo-Silva $C$, Eliashar R, Wohlgelernter J et al. Ingestion of caustic substances: a 15-year experience. Laryngoscope 2006; 116: 1422-1426.

11. Calişkan M, Türkün, Alper S. Allergy to sodium hypochlorite during root canal therapy: a case report. Int Endod J 1994; 27: 163-167.

12. Spangberg L, Engström B, Langeland K. Biologic effects of dental materials. 3. Toxicity and antimicrobial effect of endodontic antiseptics in vitro. Oral Surg Oral Med Oral Pathol 1973; 36: 856-871.

13. Baumgartner J C, Cuenin P R. Efficacy of several concentrations of sodium hypochlorite for root canal irrigation. J Endod 1992; 18: 605-612.

14. Clarkson R M, Moule A J. Sodium hypochlorite and its use as an endodontic irrigant. Aust Dent J 1998; 43: 250-256.

15. Radcliffe C E, Potouridou L, Qureshi R et al. Antimicrobial activity of varying concentrations of sodium hypochlorite on the endodontic microorganisms Actinomyces israelii, A. naeslundii, Candida albicans and Enterococcus faecalis. Int Endod J 2004; 37: 438-446

16. Giardino L, Ambu E, Becce $C$ et al. Surface tension comparison of four common root canal irrigants and two new irrigants containing antibiotic. J Endod 2006; 32: 1091-1093.

17. Mohammadi Z, Abbott PV. Review: the properties and applications of chlorhexidine in endodontics. Int Endod J 2009; 42: 288-302.

18. Sassone L M, Fidel R A, Murad C F et al. Antimicrobial activity of sodium hypochlorite and chlorhexidine by two different tests. Aust Endod J 2008; 34: 19-24

19. European Society of Endodontology. Quality guidelines for endodontic treatment: consensus report of the European Society of Endodontology. Int Endod 2006; 39: 921-930.

20. Ardizzoni $\mathrm{A}$, Blasi $\mathrm{E}$, Rimoldi $\mathrm{C}$ et al. An in vitro and ex vivo study on two antibiotic-based endodontic irrigants: a challenge to sodium hypochlorite. New Microbiol 2009; 32: 57-66.

21. Ohara P Torabinejad M Kettering J D. Antibacterial effects of various endodontic irrigants on selected anaerobic bacteria. Endod Dent Traumatol 1993; 9: 93-100.

22. Bonsor S J, Nichol R, Reid T M, Pearson G J. An alternative regimen for root canal disinfection. Br Dent J 2006; 201: 101-105.

23. Medicines and Healthcare products Regulatory Agency (MHRA). Sodium hypochlorite drug analysis. Available from http:// www.mhra.gov.uk/Safetyinformation/ Generalsafetyinformationandadvice/ Adviceandinformationforconsumers/ Druganalysisprints/ConfirmTOC/index.htm (accessed 15 February 2011). 